\title{
Valorisation of black mulberry and grape seeds: Chemical characterization and bioactive potential
}

\author{
Esther Gómez-Mejía ${ }^{\mathrm{a}, \mathrm{b}}$, Custódio Lobo Roriz ${ }^{\mathrm{a}}$, Sandrina A. Heleno ${ }^{\mathrm{a}, *}$, Ricardo Calhelha ${ }^{\mathrm{a}}$, \\ Maria Inês Dias ${ }^{\mathrm{a}}$, José Pinela ${ }^{\mathrm{a}}$, Noelia Rosales-Conrado ${ }^{\mathrm{b}}$, María Eugenia León-González ${ }^{\mathrm{b}}$, \\ Isabel C.F.R. Ferreira ${ }^{\mathrm{a}}$, Lillian Barros ${ }^{\mathrm{a}, *}$ \\ ${ }^{\text {a }}$ Centro de Investigação de Montanha (CIMO), Instituto Politécnico de Bragança, Campus Santa Apolónia, 5300-253 Bragança, Portugal \\ b Departamento de Química Analítica, Facultad de Ciencias Químicas, Universidad Complutense de Madrid, Madrid 28040, Spain
}

A R T I C L E I N F O

\section{Keywords:}

Agi-food bioresidues

Phenolic compounds

Bioactive properties

Morus nigra $\mathrm{L}$.

Vitis vinifera L. var. Albariño

\begin{abstract}
A B S T R A C T
Grape (Vitis vinifera L. var. Albariño) and mulberry (Morus nigra L.) seeds pomace were characterized in terms of tocopherols, organic acids, phenolic compounds and bioactive properties. Higher contents of tocopherols $(28 \pm 1 \mathrm{mg} / 100 \mathrm{~g} \mathrm{fw})$ were obtained in mulberry, whilst grape seeds were richer in organic acids (79 $\pm 4 \mathrm{mg} /$ $100 \mathrm{~g} \mathrm{fw})$. The phenolic analysis of hydroethanolic extracts characterised grape seeds by catechin oligomers $(36.0 \pm 0.3 \mathrm{mg} / \mathrm{g})$ and mulberry seeds by ellagic acid derivatives $(3.14 \pm 0.02 \mathrm{mg} / \mathrm{g})$. Both exhibited high antimicrobial activity against multiresistant Staphylococcus aureus MIC $=5 \mathrm{mg} / \mathrm{mL}$ ) and no cytotoxicity against carcinogenic and non-tumour primary liver (PLP) cells. Mulberry seeds revealed the strongest inhibition $(p<0.05)$ against thiobarbituric reactive substances $\left(\mathrm{IC}_{50}=23 \pm 2 \mu \mathrm{g} / \mathrm{mL}\right.$ ) and oxidative haemolysis $\left(\mathrm{IC}_{50}\right.$ at $60 \mathrm{~min}=46.0 \pm 0.8 \mu \mathrm{g} / \mathrm{mL}$ ). Both seed by-products could be exploited for the developing of antioxidant-rich ingredients with health benefits for industrial application.
\end{abstract}

\section{Introduction}

It is well-known that significant amounts of food wastes are generated worldwide, causing serious environmental issues such as greenhouse gases generation, land occupation and expenditure of resources for its treatment, among others (Ramón-Gonçalves et al., 2019). Accordingly, there has been a growing concern regarding the proper treatment of food waste through sustainable procedures (Du et al., 2018). In this perspective, the scientific community has been providing different promising solutions that include green processing technologies in combination to the use of food by-products and/or bioresidues from the food industry to obtain biofuels, biochemical products or biofertilizers (Ramón-Gonçalves et al., 2019; Du et al., 2018). Thus, the circular economy concept is increasingly seen as a crucial way for reducing waste and transforming bioresidues and by-products in valuable raw materials. Vegetal polyphenol-rich sources from agro-industrial byproducts and bioresidues as new natural preservatives, colorants or bioactives are in spotlight (Poveda et al., 2018). Over the past 30 years, natural products have received an increasing attention due to their biological benefits, being applied in pharmaceutical formulations as a strategy in reducing the risk of certain health disorders, such as cardiovascular diseases or diabetes (Zhang et al., 2018; Poveda et al., 2018). About $50 \%$ of the approved drugs, comprise natural products and it is estimated that the plant-derived drug market is to reach approximately $35 \$$ billion in 2020 (Zhang et al., 2018).

Vitis vinifera L. grape is one of the fruit crops widely cultivated in the world, with an annual production of about million metric tons (Jordão \& Cosme, 2018). Each year, the winery processing industry leads to the generation of large amounts of wastes (pomace, seeds, leen and steams among others) which account $13.5-14.5 \%$ of the total production volume. This bioresidues are normally used as fertilizers or simply discarded (Jordão \& Cosme, 2018; 2018); however, their high content of polyphenols, tocopherols and other macro- and micro- nutrients, makes winery wastes an interesting valuable raw material to obtain these molecules and use them as added-value agents for bioactive purposes (Jordão \& Cosme, 2018; Peixoto et al., 2018). Grape polyphenols are recognised as important phytochemicals, mainly due to their antioxidant and antimicrobial properties. These class of compounds consist of a wide range of different chemical structures with strong biological properties, diversely distributed in every part of the berries, although mainly present in the skin and seeds (Peixoto et al., 2018; Poveda et al., 2018).

\footnotetext{
* Corresponding authors.

E-mail addresses: sheleno@ipb.pt (S.A. Heleno), lillian@ipb.pt (L. Barros).
} 
Black mulberry (Morus nigra L.), which originates from China, is cultivated for its fruits in Southern Europe and Southwest Asia (Mosayebi \& Tabatabaei Yazdi, 2018). Mulberry fruits and leaf wastes have been widely studied (Abdel-Hamid et al., 2017; Huang et al., 2011; Koyuncu, 2004; Li et al., 2017; Mena et al., 2016; Natić et al., 2015; Okatan, 2018; Raman et al., 2016; Zhang et al., 2018); however, mulberry seeds have been underexploited, compared to grape pomace and seeds. A substantial amount of mulberry fruits is processed into juice and juice concentrates, indeed the mulberry production in Turkey exceeded 74 thousand tons (Tomas et al., 2015). Nevertheless, industrial mulberry-juice processing is accompanied by large quantities of press cake residues (mainly constituted by seeds and skin of the fruit) which are rich in antioxidants and turns this bioresidue in a potential source of bioactives (Gültekin-Özgüven et al., 2016; Mosayebi \& Tabatabaei Yazdi, 2018), such as trans-resveratrol and quercetin (Kim et al., 2010).

In a recent study, Abdel-Hamid et al. (2017) revealed the antibacterial properties of grape and mulberry leaf extracts against Staphylococcus aureus, Pseudomonas aeruginosa and Salmonella typhimurium. Additionally, Huang et al. (2011) suggested that anthocyanins from mulberry fruits might be used to prevent gastric carcinoma formation and Peixoto et al. (2018) described Vitis vinifera L. seed winery wastes as potential cytotoxic agents against MCF-7 breast adenocarcinoma and HeLa cervical carcinoma tumour cells. Consequently, the valorisation of winery and mulberry processing seed wastes can be postulated as an easily, natural and inexpensive alternative for obtaining bioactive compounds, turning these raw materials into added-value products for the food, pharmaceutical, cosmetic and other industries. Indeed, the overall market value in Europe and North America of products obtained from berry and grape food waste is estimated to exceed $4 \$$ billion by 2020 (Ghate et al., 2019).

Several authors have deal separately with the chemical or the bioactive characterisation of grape or mulberry wastes (Abdel-Hamid et al., 2017; Aldubayan, 2018; Dopico-García et al., 2007; Poveda et al., 2018). However, few have addressed the individual characterization and the multiple bioactive properties of grape (Peixoto et al., 2018), and mulberry seeds (Kim et al., 2010). Therefore, there is still a lack of literature information involving similar combination of raw material types and multiple bioactive characterisation, together with their phenolic profile. Thus, the aim of this study was to chemically characterise the grape and mulberry seeds in terms of bioactive compounds, namely organic acids, tocopherols and phenolic compounds. Furthermore, it was also intended to evaluate their bioactive potential regarding the antioxidant, antihaemolytic, cytotoxic and antimicrobial properties. This study contributed to valorisation of natural resources, highlighting the valorisation of food waste and the obtaining of added-value molecules with biological effects, being powerful candidates for the industrial application.

\section{Material and methods}

\subsection{Grape and mulberry seed}

Black mulberry seeds were obtained after juice making from mulberry fruits (Morus nigra L.), provided by the Portuguese enterprise "Ponto Agricola Lda.". Washed black mulberries were mechanical milled (WORTEN Juice Machine WFE-2, WORTEN, P.R.C.) at room temperature $\left(25-27^{\circ} \mathrm{C}\right)$. The pulp was recovered, and the seeds waste was collected in triplicate after independent processing events. Mulberry seeds waste was analysed within 2 months after the juice making.

Grape seeds (Vitis vinifera L. var. Albariño) were provided by a Spanish winery from Galicia, Terras Gauda. The grape bioresidue was obtained by manual sieving of the bagasse obtained after industrial pressing. Subsequently, the sample was subjected to an extraction of essential oils, where the seeds were separated, air-dried at $30{ }^{\circ} \mathrm{C}$ for
$48 \mathrm{~h}$, and following subjected to an extraction of essential oils by cold pressing. Therefore, the sample analysed in this study was the remaining bioresidue after the wine production and the essential oils extraction.

Both samples were homogenised using a mechanical grinder (Molineux AR110830) at room temperature $\left(25^{\circ} \mathrm{C}\right)$. Samples were reduced to fine powder (20 mesh), transferred to hermetic containers and stored under refrigeration at $-20{ }^{\circ} \mathrm{C}$ to prevent degradation.

\subsection{Preparation of hydroethanolic extracts}

Black mulberry and grape seed by-products extracts were obtained applying a green and simple solid-liquid extraction previously described by Peixoto et al. (2018). A dynamic maceration with a hydroethanolic solution (80:20 v/v ethanol-water) was performed mixing $1 \mathrm{~g}$ of sample with $30 \mathrm{~mL}$ of the hydroethanolic solution, continuously stirred at room temperature for $1 \mathrm{~h}$ (VELP Scientifica heating-magnetic stirrer). The obtained mixture was then filtered through a Whatman paper filter N.4, and the residue re-extracted by repeating the procedure. Then the gathered filtrates where subjected to an evaporation procedure in a rotatory evaporator (Buchi R-2010) to remove the ethanol. The remained water solution was frozen and lyophilized (FreeZone 4.5, Labconco, USA).

\subsection{Chemical characterization}

\subsubsection{Analysis of organic acids}

Extraction and determination of organic acids were carried out following the procedure described by Barros et al. (2013) with some modifications. Concisely, $1 \mathrm{~g}$ of the sample was magnetic stirred with $25 \mathrm{~mL}$ of $\mathrm{HPO}_{3} 4.5 \%$ (w/v) aqueous solution, for $20 \mathrm{~min}$ at $25{ }^{\circ} \mathrm{C}$ and filtered through a paper filter. Finally, extracts were filtered again through a nylon syringe filter $(0.2 \mu \mathrm{m}$ poro size (Membrane Solutions, Kent, WA, USA)) prior to chromatographic analysis. Samples were analysed in triplicate. Organic acid analysis was performed using a Shimadzu 20A series UFLC (Shimadzu Corporation, Kyoto, Japan) equipped with a DGU-20A degasser, a Nexera SIL-20A autosampler with temperature-controlled tray, a CTO-20AS column oven, and a SPDM20A photodiode array detector (PDA). Separation was accomplished using a mobile phase isocratic elution, based on sulphuric acid $3.6 \mathrm{mM}$, and a SphereClone C18 $(250 \times 4.6 \mathrm{~mm}, 5 \mu \mathrm{m})$ analytical column (Phenomenex, Torrance, CA, USA), operating at $35^{\circ} \mathrm{C}$. Flow rate was set at $0.80 \mathrm{~mL} \cdot \mathrm{min}^{-1}$ and the UV detection was fixed at 215 and $245 \mathrm{~nm}$. Quantitative analyses were performed at $245 \mathrm{~nm}$ for ascorbic acid and at $215 \mathrm{~nm}$ for citric, fumaric, malic, oxalic, quinic, shikimic and succinic acids, bought from Sigma (St Louis, MIO, USA). Organic acids were identified based on the adjusted retention time and the peak purity compared to those of analytical standard solutions. Quantification was based on external calibration curves obtained from commercial standards of each analyte. Results were recorded and processed using LabSolutions Multi LC-PDA software (Shimadzu Corporation, Kyoto, Japan), and expressed in $\mathrm{g}$ per $100 \mathrm{~g}$ of fresh weight (fw).

\subsubsection{Analysis of tocopherols}

Tocopherols were determined using the methodology previously descried by Barros et al. (2013). Briefly, an organic extract was obtained from subsequently mixing $500 \mathrm{mg}$ of the sample with $4 \mathrm{~mL}$ of $\mathrm{MeOH}, 4 \mathrm{~mL}$ of a saturated solution of $\mathrm{NaCl}$ and $4 \mathrm{~mL}$ of hexane, the hexane phase is separated into a new container, and the hexane addition and removal is repeated twice. The hexane extract is taken to dryness under a nitrogen stream and finally re-dissolved in $2 \mathrm{~mL}$ of hexane. Tocol, purchased from Matreya (Plasanr Gap, PA, USA) $(50 \mu \mathrm{g}$ / $\mathrm{mL}$, hexane) was employed as an internal standard and samples were analysed in triplicate.

Chromatographic analysis of tocopherols was performed by a liquid chromatography equipment consisted on an integrated system with a 
pump (Knauer, Smartline system 1000, Berlin, Germany), degasser system (Smartline manager 5000), autosampler (AS-2057 Jasco, Easton, MD, USA) and column oven (7971 R Grace oven) coupled to a fluorescence detector (FP-2020 Jasco, Easton, MD, USA). Separation was accomplished using a mobile phase isocratic elution, based on a mixture of hexane and ethyl acetate 70:30 (v/v) purchased from LabScan (Lisbon, Portugal), and a polyamide II $(250 \mathrm{~mm} \times 4.6 \mathrm{~mm}$ i.d., $5 \mu \mathrm{m}$ ) analytical column supplied by YMC (Kyoto, Japan), operating at $30{ }^{\circ} \mathrm{C}$. Flow rate was set at $1.0 \mathrm{~mL} \cdot \mathrm{min}^{1}$, injection volume was fixed to $20 \mu \mathrm{L}$ and the fluorescence detector (FP-2020 Jasco, Easton, MD, USA) was programmed for excitation at $290 \mathrm{~nm}$ and emission at $330 \mathrm{~nm}$.

The identification of target analytes was based on the adjusted retention time and the peak purity compared to those of analytical standard solutions bought from Sigma (St Louis, MIO, USA). Quantification was based on calibration curves $(n=7)$ within the range $0.125-8.0 \mu \mathrm{g} / \mathrm{mL}$, obtained from commercial standards of each analyte using the internal standard methodology. Data were recorded and processed using a Clarity 2.4 software (DataApex, Prague, Czech, Republic) and results were expressed in milligram of tocopherol per $100 \mathrm{~g}$ of sample fw.

\subsubsection{Analysis of phenolic compounds}

The dried extracts previously obtained were submitted to a purification prior to chromatographic analysis. An amount of $100 \mathrm{mg}$ of the lyophilized extract was dissolved in $4 \mathrm{~mL}$ of EtOH and transferred into a Sep-Pak C18 3 cc Vac Cartridge (Phenomex, Torrance, CA, USA). After a water-cleaning step $(5 \mathrm{~mL})$, the analytes were eluted with $5 \mathrm{~mL}$ of $\mathrm{MeOH}$. The eluate was evaporated to dryness (Buchi R-2010 rotary evaporator) and finally re-dissolved in $1 \mathrm{~mL}$ of $\mathrm{MeOH}$-water 20:80 ( $v /$ $v$ ). The phenolic profile was determined by liquid chromatography (Dionex Ultimate 3000 UPLC, Thermo Scientific, San Jose, CA, USA), with diode-array detector (280, 330 and $370 \mathrm{~nm}$ wavelengths) equipped with an ESI source and working in negative mode (Linear Ion Trap LTQ XL, Thermo Scientific, San Jose, CA, USA) (Bessada et al., 2016). Chromatographic separation was achieved with a WatersSpherisorb S3 ODS-2C18 ( $3 \mathrm{~m}, 4.6 \mathrm{~mm} \times 150 \mathrm{~mm}$, Waters, Mil-ford, MA, USA) column thermostated at $35 \circ \mathrm{C}$. The solvents used were: (A) $0.1 \%$ formic acid in water, (B) acetonitrile. The elution gradient established was isocratic $15 \% \mathrm{~B}(5 \mathrm{~min}), 15 \%$ B to $20 \%$ B (5 min), $20-25 \%$ B (10 min), 25-35\% B(10 min), 35-50\% B (10 min), and re-equilibration of the column, using a flow rate of $0.5 \mathrm{~mL} / \mathrm{min}$ (Bessada et al., 2016). For quantification purposes, 7-level external calibration curves were obtained for phenolic patterns. In those cases, where there was no commercial availability of the compounds, the quantification was achieved through the most similar available standard. Results were recorded and processed using Xcalibur data system (Thermo Finnigan, San Jose, CA, USA), and following expressed in $\mathrm{mg}$ per gram of extract.

\subsection{Bioactive properties of hydroethanolic extracts from Morus nigra and} Vitis vinifera var. Albariño seeds

\subsubsection{Antioxidant activity}

The antioxidant activity of the extracts was evaluated by the thiobarbituric acid reactive substances (TBARS) colorimetric method, described by Pinela et al. (2012) with slight modifications. The obtained extracts were re-dissolved in water to obtain a stock solution $(1.0 \mathrm{mg} /$ $\mathrm{mL}$ ), subsequently diluted in ten different working concentrations. The evaluation of the lipid peroxidation inhibition in porcine brain homogenates results from the reduction of TBARS by the formation of the malondialdehyde-thiobarbituric acid complex (MDA-TBA). The colour intensity displayed by this complex in the different working concentrations was measured by its absorbance at $532 \mathrm{~nm}$ (UV-Vis Specord 200 spectrophotometer, Analytik Jena, Jena, Germany). The results were expressed in values of $\mathrm{EC}_{50}$, concentration of sample necessary to obtain $50 \%$ of antioxidant activity.

The oxidative haemolysis inhibition assay (OxHLIA) was performed as described by Lockowandt et al. (2019). Briefly, an erythrocyte solution $(2.8 \%$ in PBS, $v / v ; 200 \mu \mathrm{L})$ was mixed with $400 \mu \mathrm{L}$ of either extract solution in PBS (200-6.25 $\mu \mathrm{g} / \mathrm{mL}$ ), PBS solution (control), or water (for ensuring complete haemolysis) in a 48 -well plate. After preincubating the mixture at $37{ }^{\circ} \mathrm{C}$ for $10 \mathrm{~min}$ with shaking in a temperature-controlled microplate reader (Bio-Tek Instruments Inc., ELX800, Winooski, VT, USA), 2-2'-azobis(2-methylpropionamidine) dihydrochloride (AAPH, $160 \mathrm{mM}$ in PBS; $200 \mu \mathrm{L}$ ) was added and the optical density $(690 \mathrm{~nm})$ was measured every $10 \mathrm{~min}$ in a microplate reader until complete haemolysis. The assay was performed in duplicate. Trolox purchase from Sigma-Aldrich (St. Louis, MIO, USA) was the positive control. The results were expressed as $\mathrm{IC}_{50}$ values $(\mu \mathrm{g} / \mathrm{mL})$ at $\Delta t$ of $60 \mathrm{~min}$ and $120 \mathrm{~min}$.

\subsubsection{Cytotoxicity}

The cytotoxic activity of the lyophilised extracts re-dissolved in water $(5-400 \mu \mathrm{g} / \mathrm{mL})$ against tumour cells was evaluated by the sulforhodamine B (SRB) colorimetric method, previously described by Vaz et al. (2010). Four different human tumour cell lines were evaluated: MCF-7 (breast adenocarcinoma), HepG2 (hepatocellular carcinoma) and NCI-H460 (non-small cell lung carcinoma), and HeLa (cervical carcinoma). Briefly, the used cell lines were routinely maintained as adherent cell cultures in RPMI-1640 containing heat-inactivated FBS (10\%), glutamine $(2 \mathrm{mM})$, penicillin $(100 \mathrm{U} / \mathrm{mL})$, and streptomycin $(100 \mu \mathrm{g} / \mathrm{mL})$ and were further incubated at $37{ }^{\circ} \mathrm{C}$ with humidified air and $5 \% \mathrm{CO}_{2}$ (Cell Culture ${ }^{\circledR} \mathrm{CO} 2$ Incubator, ESCO GB Ltd., UK).

Afterwards, the cell lines were plated in 96-well microplates, along with the different dilutions of the extract under analysis and incubated for $48 \mathrm{~h}$ at $37{ }^{\circ} \mathrm{C}$ with $5 \% \mathrm{CO}_{2}$. The adherent cells were fixed by the addition of $10 \%$ trichloroacetic acid previously refrigerated $(100 \mu \mathrm{L})$, incubated for $60 \mathrm{~min}$ at $4{ }^{\circ} \mathrm{C}$, washed with deionized water and dried. After this process, SRB $(0.1 \%$ in $1 \%$ acetic acid, $100 \mu \mathrm{L})$ was then added to the wells of the microplate and incubated for $30 \mathrm{~min}$ at room temperature. Subsequently, non-adhered SRB was removed by washing with $1 \%$ acetic acid solution and the plate was allowed to dry. The adhered SRB was solubilized with $10 \mathrm{mM}$ Tris $(200 \mu \mathrm{L})$ and the absorbance was read at a wavelength of $540 \mathrm{~nm}$ in the microplate reader (ELX800). Additionally, a primary cellular line from porcine liver (PLP) was used as a normal cell line to achieve the extracts toxicity. The antiproliferative activity was assessed as the extract concentration providing $50 \%$ of cell growth inhibition $\left(\mathrm{GI}_{50}, \mu \mathrm{g} / \mathrm{mL}\right)$.

\subsubsection{Antimicrobial activity}

The antimicrobial activity of the lyophilised extracts re-dissolved in water $(0.156-20 \mathrm{mg} / \mathrm{mL})$ were tested against six Gram-negative (Escherichia coli, Klebsiella pneumoniae, Morganella morganii, Pseudomonas aeruginosa, Neisseria gonorrhoeae and Proteus mirabilis), three Gram-positive bacteria (methicillin-resistant Staphylococcus aureus (MRSA), Listeria monocytogenes and Enterococcus faecalis), and a yeast (Candida albicans); all of them clinical isolated from patients hospitalized in North-eastern Portuguese hospitals.

The antimicrobial potential was evaluated through the microdilution method and the rapid p-iodonitrotetrazolium chloride (INT, Panreac Applichem, Barcelona, Spain) colorimetric assay as previously described Pires et al. (2018), slightly modified. Briefly, $100 \mu \mathrm{L}$ of each extract concentration $(0.156-20 \mathrm{mg} / \mathrm{mL})$ was mixed with $100 \mu \mathrm{L}$ of Tryptic Soy Broth (TSB, Biolab (Budapest, Hungry)) and $10 \mu \mathrm{L}$ of bacteria suspension in sterile water at $1.5 \times 10^{8} \mathrm{CFU} / \mathrm{mL}$. For each inoculum, one positive control of bacteria suspension and TSB, and two other negative controls of non-inoculated TSB and seed extracts, respectively, were prepared. After the incubation at $37{ }^{\circ} \mathrm{C}$ for $18-24 \mathrm{~h}$ (36 $\mathrm{h}$ in the case of the Candida albicans yeast) (Laboratory incubator CLW 240, Pol-Eko Apararura SP.J., Poland), the reactions were visually screened regarding the colour change following the addition of INT dye ( $40 \mu \mathrm{L}$ at $0.2 \mathrm{mg} / \mathrm{mL}$ ). Antibacterial results were expressed as Minimal Inhibitory Concentrations (MIC; $\mathrm{mg} / \mathrm{mL}$ ). 
Table 1

Organic acids and tocopherols composition of mulberry (Morus nigra) and grape (Vitis vinifera var. Albariño) seeds.

\begin{tabular}{|c|c|c|}
\hline & Morus nigra & Vitis vinifera var. Albariño \\
\hline \multicolumn{3}{|c|}{ Organic acids (mg/100 $g$ fw) } \\
\hline Oxalic acid & $2.5 \pm 0.1^{*}$ & $38.9 \pm 0.7 *$ \\
\hline Quinic acid & n.d. & $40 \pm 3$ \\
\hline Malic acid & tr. & tr. \\
\hline Fumaric acid & tr. & tr. \\
\hline Total organics & $2.5 \pm 0.1^{*}$ & $79 \pm 4^{*}$ \\
\hline \multicolumn{3}{|c|}{ Tocopherols $(\mathrm{mg} / 100 \mathrm{~g} f \mathrm{w})$} \\
\hline$\alpha$-tocopherol & $0.73 \pm 0.03^{*}$ & $0.05 \pm 0.01 *$ \\
\hline$\beta$-tocopherol & n.d. & n.d. \\
\hline$\gamma$-tocopherol & $25 \pm 1^{*}$ & $0.119 \pm 0.002^{*}$ \\
\hline$\delta$-tocopherol & $2.2 \pm 0.2$ & n.d. \\
\hline Total tocopherols & $28 \pm 1^{*}$ & $0.17 \pm 0.01 *$ \\
\hline
\end{tabular}

Calibration curves for organic acids: oxalic acid $(\mathrm{y}=10 \mathrm{E}+07 \mathrm{x}+231891$, R2 = 0.9999; LOD = $12.6 \mu \mathrm{g} / \mathrm{mL} ; \mathrm{LOQ}=41.8 \mu \mathrm{g} / \mathrm{mL}) ;$ quinic acid $(\mathrm{y}=671557 \mathrm{x}+14583, \mathrm{R} 2=0.9998 ; \mathrm{LOD}=24.18 \mu \mathrm{g} / \mathrm{mL} ; \mathrm{LOQ}=80.61 \mu \mathrm{g} /$ $\mathrm{mL})$; malic acid $(\mathrm{y}=950041 \mathrm{x}+6255.6 \mathrm{R} 2=0.9999)$; fumaric acid $(\mathrm{y}=1 \mathrm{E}+08 \mathrm{x}+614399, \mathrm{R} 2=0.9986 ; \mathrm{LOD}=0.08 \mu \mathrm{g} / \mathrm{mL} ; \mathrm{LOQ}=0.26 \mu \mathrm{g} /$ $\mathrm{mL}$ ). $\alpha$-Tocopherol (LOD $=18.06 \mathrm{ng} / \mathrm{mL}, \mathrm{LOQ}=60.20 \mathrm{ng} / \mathrm{mL}$ ); $\beta$-tocopherol $(\mathrm{LOD}=25.82 \mathrm{ng} / \mathrm{mL}, \mathrm{LOQ}=86.07 \mathrm{ng} / \mathrm{mL}) ; \gamma$-tocopherol $(\mathrm{LOD}=14.79 \mathrm{ng} /$ $\mathrm{mL}, \mathrm{LOQ}=49.32 \mathrm{ng} / \mathrm{mL}$ ) and $\delta$-tocopherol (LOD $=20.09 \mathrm{ng} / \mathrm{mL}$, LOQ $=66.95 \mu \mathrm{g} / \mathrm{mL}$ ). n.d.- not detected; tr. - traces; *t-Student test $p$ value $>0.001$.

\subsection{Statistical analysis}

The chemical composition and antioxidant activity data, of both seed samples, were explored and compared by means of $t$-Student analysis. Statgraphics Centurion 18 (Statgraphics Technologies. Inc, Rockville, MD, USA) software package, running under Windows 10, was used for applying the statistical analysis.

\section{Results and discussion}

\subsection{Chemical characterization of Morus nigra and Vitis vinifera var. Albariño seeds extracts}

\subsubsection{Composition in organic acids}

Among the constituents of plants and their derivatives, organic acids play an essential role in their development not only for their intervention in important metabolic pathways, but also for supporting the adaptation of the plant to environmental changes (Lockowandt et al., 2019; Koyuncu, 2004). Furthermore, organic acids have been used as natural preservatives and extensively employed as food additives and stabilizers (Mohan \& Pohlman, 2016). As it can be seen in Table 1, oxalic, malic and fumaric acids were found in both kind of seeds. No significance differences were obtained when oxalic acid contents were compared in both species; whilst malic and fumaric acids could not be compared due to their low concentration (traces). Moreover, quinic acid was only determined in grape seeds. Oxalic acid was the most abundant organic acid found in mulberry seeds at concentration of $2.5 \pm 0.1 \mathrm{mg} / 100 \mathrm{~g}$ fw. Previously, Koyuncu (2004) described the presence of oxalic $(0.62 \mathrm{mg} / \mathrm{g})$, malic $(89.96 \mathrm{mg} / \mathrm{g})$ and fumaric $(0.019 \mathrm{mg} / \mathrm{g})$ acids in mulberry fruits. In this study, malic acid was determined as the major compound and higher amounts were reported for each organic acid. This fact could be attributable to the distribution of organic acids in fruits, which are mainly accumulated in the flesh and not in the seeds, added to the different geographical origin of mulberry samples (Koyuncu; 2004).

Regarding grape seeds, both oxalic (38.9 $\pm 0.7 \mathrm{mg} / 100 \mathrm{~g} \mathrm{fw})$ and quinic (40 $\pm 3 \mathrm{mg} / 100 \mathrm{~g} \mathrm{fw}$ ) acids were determined in higher contents, with no significant difference between their amounts at $95 \%$ confidence level, when $t$-Student test was performed. Similarly, Dopico-
García et al. (2007) determined oxalic $(0.42 \mathrm{mg} / \mathrm{g})$, malic $(1.86 \mathrm{mg} / \mathrm{g})$ and fumaric (0.0044) acids in white "vinho verde" grapes. In consonance with the results shown in Table 1, fumaric acid was present at trace levels and the concentration of oxalic acid was in the same order of magnitude, though malic acid was the majoritarian. Again, the discrepancies in the results found in the literature are likely ascribable to the distribution of organic acids in fruits, genotype and variety of the grapes (Koyuncu, 2004).

According to total organic amounts, grape seeds were richer in organic acids than mulberry seeds, finding out a significant difference between the amounts of the seeds at a 95\% confidence level. Therefore, the presence of these bioactive compounds in the studied seeds, exhibits a potential exploitation of these by-products, mainly grape seeds, as natural sources of oxalic and quinic acids, which may be used as food preservatives.

\subsubsection{Composition in tocopherols}

Tocopherols are among the most important lipid-soluble antioxidants in food as well as in the human and animal tissues. Tocopherols are found in lipid-rich regions of cells and fat depots grape (Sabir, Unver \& Kara, 2012) and thus fruit seeds are a feasible source of these compounds. Among the four isoforms, $\gamma$-tocopherol was the most abundant one in both seeds at $25 \pm 1 \mathrm{mg} / 100 \mathrm{~g}$ fw in mulberry and $0.119 \pm 0.002 \mathrm{mg} / 100 \mathrm{~g}$ fw in grape seeds, finding particularly higher amounts in the case of mulberry seeds (Table 1). The $\alpha$-isoforms was also identified in both samples at considerably lower concentration $(0.73 \pm 0.03 \mathrm{mg} / 100 \mathrm{~g} \mathrm{fw}$ in mulberry and $0.05 \pm 0.01 \mathrm{mg} / 100 \mathrm{~g} \mathrm{fw}$ in grape seeds); meanwhile, $\delta$-tocopherol was only determined in mulberry seeds $(2.2 \pm 0.2 \mathrm{mg} / 100 \mathrm{~g} \mathrm{fw})$. By comparison of the two seed samples, it can be stated that significant differences were obtained for each isoform. Additionally, the total tocopherol content from mulberry seeds was considerably higher than the one found in grape seeds. This fact could be due to the previous drying and extrusion processes, to which the winey bioresidue was subjected for the extraction of essential oils; since tocopherols are quite sensitive to factors such as temperature, light, pressure, among others (Sabliov et al., 2009).

Particularly interesting is the presence of $\alpha$ - and $\gamma$-isoforms in the seed by-products, thus only $\alpha$ - and $\gamma$-tocopherols show antioxidant activity and nutritional significance (Sabliov et al., 2009); increasing the importance of these bioresidues. The presence of both isoforms, $\alpha$ - and $\gamma$-, have been also reported in seed oil by-product from grape (Sabir, Unver \& Kara, 2012) and mulberry (Kim et al., 2010) from winery and juice industries. Similar amounts were described for $\gamma$-tocopherol in mulberry seeds (18 mg/100 g), although higher concentrations were obtained in grape seed oil (1.4-3.0 mg/100 g).

\subsubsection{Profile in phenolic compounds}

Table 2 presents the data obtained for the phenolic profile identification and quantification by HPLC-DAD-MS analysis in M. nigra and $V$. vinifera samples. A total of twenty-seven compounds were tentatively identified in the grape and mulberry seeds. The detected compounds belonged to the groups of phenolic acids (rosmarinic acid and ellagic acid derivatives), flavan-3-ols ((epi)catechin oligomers), and flavonoids (quercetin, isorhamnetin, and taxifolin glycosylated derivatives). The tentative identification of $V$. vinifera sample followed, and is in accordance with, the previously reported phenolic profile by Peixoto et al. (2018), and Petropulos et al. (2014) in V. vinífera plant. Regarding the phenolic characterization of $M$. nigra, the tentative identification followed, and is in accordance with, the previously reported phenolic profile by Natić et al. (2015), Li et al. (2017) in Morus alba L., and by Mena et al. (2016) in M. alba and M. nigra. However, for the identification of the flava-3-ol derivatives in $M$. nigra, the tentative identification was made in accordance with the literature used for $V$. vinifera.

Overall, grape seeds were considerably richer in total phenolic compound (45.7 $\pm 0.2 \mathrm{mg} / \mathrm{g}$ of extract) than mulberry seeds (8.02 $\pm 0.05 \mathrm{mg} / \mathrm{g}$ of extract); which is in accordance with the quite 
Table 2

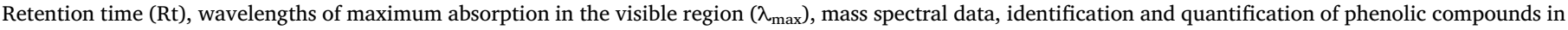
black mulberry (Morus nigra L.) and grape (Vitis vinifera L. var. Albariño) seed extract (mean \pm SD).

\begin{tabular}{|c|c|c|c|c|c|c|c|}
\hline Peak & Rt (min) & $\lambda_{\max }(\mathrm{nm})$ & {$[\mathrm{M}-\mathrm{H}]^{-}(m / z)$} & $\mathrm{MS}^{2}$ & Tentative identification & M. nigra (mg/g) & V. vinifera $(\mathrm{mg} / \mathrm{g})$ \\
\hline 1 & 5.24 & 277 & 577 & $451(29), 425(100), 407(25), 289(15)$ & Type B (epi)catechin dimer ${ }^{\mathrm{A}}$ & - & $3.1 \pm 0.2$ \\
\hline 2 & 6.03 & 277 & 633 & $301(100)$ & Galloyl-HHDP*-glucose $\mathrm{D}^{\mathrm{D}}$ & $0.102 \pm 0.003$ & - \\
\hline 3 & 6.1 & 280 & 577 & $451(29), 425(100), 407(25), 289(15)$ & Type B (epi)catechin dimer ${ }^{\mathrm{A}}$ & - & $3.2 \pm 0.1$ \\
\hline 4 & 6.75 & 280 & 289 & 245(35), 203(14), 137(21) & $(+)$-Catechin ${ }^{\mathrm{A}}$ & - & $3.88 \pm 0.04$ \\
\hline 5 & 7.14 & 279 & 577 & $451(29), 425(100), 407(25), 289(15)$ & Type B (epi)catechin dimer ${ }^{\mathrm{A}}$ & $1.56 \pm 0.01$ & - \\
\hline 6 & 7.17 & 280 & 577 & $451(29), 425(100), 407(25), 289(15)$ & Type B (epi)catechin dimer ${ }^{\mathrm{A}}$ & - & $3.9 \pm 0.1$ \\
\hline 7 & 7.75 & 280 & 865 & $577(43), 451(14), 425(16), 407(12), 289(11)$ & Type B (epi)catechin trimer ${ }^{\mathrm{A}}$ & - & $3.8 \pm 0.1$ \\
\hline 8 & 7.81 & 279 & 865 & $577(43), 451(14), 425(16), 407(12), 289(11)$ & Type B (epi)catechin trimer ${ }^{\mathrm{A}}$ & $1.34 \pm 0.03$ & - \\
\hline 9 & 9.10 & 276 & 783 & $481(5), 301(100)$ & bis-HHDP-glucose ${ }^{\mathrm{D}}$ & $0.100 \pm 0.001$ & - \\
\hline 10 & 9.27 & 280 & 289 & 245(35), 203(14), 137(21) & $(-)$-Epicatechin ${ }^{\mathrm{A}}$ & - & $3.7 \pm 0.1$ \\
\hline 11 & 9.90 & 277 & 783 & $481(5), 301(100)$ & bis-HHDP-glucose $\mathrm{D}^{\mathrm{D}}$ & $0.104 \pm 0.001$ & - \\
\hline 12 & 11.04 & 280 & 865 & $577(43), 451(14), 425(16), 407(12), 289(11)$ & Type B (epi)catechin trimer ${ }^{\mathrm{A}}$ & - & $3.7 \pm 0.1$ \\
\hline 13 & 11.52 & 277 & 935 & $633(25), 301(60)$ & Galloyl-bis-HHDP-glucose ${ }^{\mathrm{D}}$ & $0.31 \pm 0.01$ & - \\
\hline 14 & 12.26 & 279 & 1153 & 865(22), 713(4), 577(33), 575(16), 561(20), 289(100) & Type B (epi)catechin tetramer ${ }^{\mathrm{A}}$ & - & $6.0 \pm 0.1$ \\
\hline 15 & 12.74 & 279 & 935 & $633(100), 301(22)$ & Galloyl-bis-HHDP-glucose ${ }^{\mathrm{D}}$ & $0.89 \pm 0.02$ & - \\
\hline 16 & 13.74 & 282 & 935 & $633(100), 301(31)$ & Galloyl-bis-HHDP-glucose ${ }^{\mathrm{D}}$ & $0.17 \pm 0.01$ & - \\
\hline 17 & 13.97 & 280 & 865 & $577(43), 451(14), 425(16), 407(12), 289(11)$ & Type B (epi)catechin trimer ${ }^{\mathrm{A}}$ & - & $4.23 \pm 0.02$ \\
\hline 18 & 15.6 & 280 & 865 & $577(43), 451(14), 425(16), 407(12), 289(11)$ & Type B (epi)catechin trimer ${ }^{\mathrm{A}}$ & - & $5.0 \pm 0.1$ \\
\hline 19 & 17.05 & $252 / 359$ & 433 & $301(100)$ & Ellagic acid pentoside ${ }^{B}$ & $0.446 \pm 0.002$ & - \\
\hline 20 & 17.39 & 280 & 865 & $577(43), 451(14), 425(16), 407(12), 289(11)$ & Type B (epi)catechin trimer ${ }^{\mathrm{A}}$ & - & $3.2 \pm 0.1$ \\
\hline 21 & 17.57 & $252 / 360$ & 433 & $301(100)$ & Ellagic acid pentoside ${ }^{B}$ & $0.82 \pm 0.04$ & - \\
\hline 22 & 18.01 & 358 & 477 & $301(100)$ & Quercetin-O-glucuronide ${ }^{B}$ & $0.52 \pm 0.02$ & - \\
\hline 23 & 18.06 & $280, \operatorname{sh} 337$ & 449 & $303(100)$ & Taxifolin-O-rhamnoside ${ }^{\mathrm{B}}$ & - & $0.38 \pm 0.01$ \\
\hline 24 & 18.76 & $252 / 363$ & 301 & $257(100), 185(5)$ & Ellagic acid $^{\mathrm{D}}$ & $0.206 \pm 0.002$ & - \\
\hline 25 & 21.67 & 320 & 359 & $197(22), 179(37), 161(100), 135(5)$ & Rosmarinic acid $^{\mathrm{C}^{* * *}}$ & $0.84 \pm 0.04$ & $1.7 \pm 0.1$ \\
\hline 26 & 22.22 & 352 & 447 & $315(100)$ & Isorhamnetin-O-hexoside ${ }^{\mathrm{B}}$ & $0.306 \pm 0.001$ & - \\
\hline \multirow[t]{5}{*}{27} & 23.57 & 352 & 447 & $315(100)$ & Isorhamnetin-O-hexoside $^{\mathrm{B}}$ & $0.304 \pm 0.001$ & - \\
\hline & & & & & Total Phenolic Acids** & $2.7 \pm 0.1$ & $1.7 \pm 0.1$ \\
\hline & & & & & Total Flavan-3-ol & $2.92 \pm 0.02$ & $43.6 \pm 0.3$ \\
\hline & & & & & Total Other Flavonoids** & $2.40 \pm 0.02$ & $0.38 \pm 0.01$ \\
\hline & & & & & Total Phenolic Compounds** & $8.02 \pm 0.03$ & $45.7 \pm 0.2$ \\
\hline
\end{tabular}

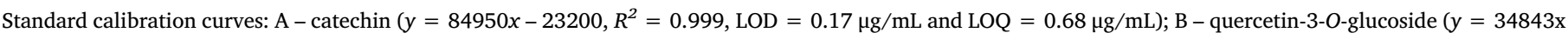

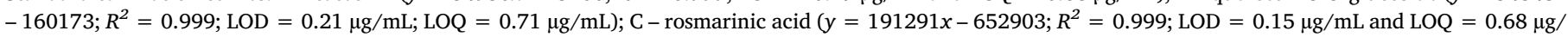

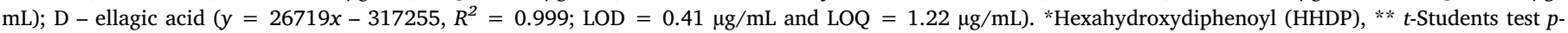
value $>0.001$.

different antioxidant profile obtained. The flavan-3-ol derivatives group was the predominant one in both samples, achieving an amount of $43.6 \pm 0.3 \mathrm{mg} / \mathrm{g}$ of extract in grape seeds and $2.92 \pm 0.02 \mathrm{mg} / \mathrm{g}$ of extract in mulberry seeds, mainly due to the presence of type B (epi) catechin trimer and type B (epi)catechin dimer, respectively. The group of proanthocyanidins make up to $95 \%$ of the total phenolic compounds determined, $16 \%$ as monomers and $79 \%$ as oligomers (Table 2). These results are in accordance with Bai et al. (2019) which have reported grape seeds as one of the nature's abundant sources of proanthocyanidins; ranging from $13 \%$ to $89 \%$ of the extracts as polymers. Type B catechins were also found in mulberry seeds, although at lower concentration, $1.564 \pm 0.007 \mathrm{mg} / \mathrm{g}$ for type-B dimer and $1.34 \pm 0.03 \mathrm{mg} / \mathrm{g}$ for type-B trimer (Table 2). Therefore, both byproducts, but mainly grape seeds, can be proposed as a readily-exploitable source of catechin and conjugates; which additionally have been correlated with several biological effects on human health, including antioxidant, anti-inflammatory and cardioprotective effects (Bai et al., 2019).

The ellagic acid and its derivatives were exclusively found in mulberry seeds (Table 2). They represent the $41 \%$ of the total phenolic compounds found in mulberry seeds (3.14 $\pm 0.02 \mathrm{mg} / \mathrm{g}$ of extract). Okatan (2018) also identified ellagic acid in $M$. nigra fruits, collected from several regions of Turkey. Lower concentrations were determined ranging from 1.36 to $5.40 \mathrm{mg} / 100 \mathrm{~g}$, which can be attributed to the extraction procedures and the diverse genetic and climatic conditions of the samples evaluated (Okatan, 2018).

Additionally, rosmarinic acid was the only phenolic compound detected in both waste samples, at a concentration of $1.72 \pm 0.06 \mathrm{mg} / \mathrm{g}$ and $0.84 \pm 0.04 \mathrm{mg} / \mathrm{g}$ in grape and mulberry seed extracts respectively. Statistically significant higher amounts ( $t$-Students test) were found in grape seeds in comparison to mulberry seeds. Using rosmarinic acid as a natural feed supplement has been described to exert multiple health benefits as an endocrine and immune stimulant, an antimicrobial, anthelminthic and anti-inflammatory agent (Alagawany et al., 2017); which promotes the use of grape seed extracts in the agrifood industry.

Concerning flavonoids, the glucoside flavanonol taxifolin-O-rhamnoside was only determined in grape seeds as the minor compound $(0.382 \pm 0.008 \mathrm{mg} / \mathrm{g}$ of extract). Meanwhile in mulberry seeds, the flavonols quercetin-O-glucuronide and isorhamnetin-O-hexoside were found at concentration range from 0.304 to $0.52 \mathrm{mg} / \mathrm{g}$ of extract; achieving a $17 \%$ of the total phenolic compounds determined. Although in the mulberry and grape seeds evaluated, flavonoids are presented at a lower concentration in comparison with proanthocyanidins, these compounds are greatly priced in the industrial sector due to their ability to preserve foods, provide flavour and make dietary supplements, giving an added-value to these by-products (Cushnie \& Lamb, 2005; Peixoto et al., 2018; Poveda et al., 2018).

\subsection{Bioactivity of the seeds extracts}

\subsubsection{Antioxidant activity}

The antioxidant activity of mulberry and grape seed extracts was tested using two in vitro cell-based assays. The lipid peroxidation inhibition was assessed by the capacity to inhibit the formation of thiobarbituric acid reactive substances using porcine brain tissues as biological substrates. This assay was developed to estimate the magnitude of oxidative damage caused to lipid membranes by oxidative agents, such as free radicals. The extent of the peroxidation reaction was determined through spectrophotometric monitoring of the degradation 
Table 3

In vitro antioxidant and antimicrobial activities of grape (Vitis vinifera var. Albariño) and mulberry (Morus nigra) seed extracts and positive controls.

\begin{tabular}{|c|c|c|c|c|c|}
\hline & Mulberry seeds & Grape seeds & \multicolumn{3}{|l|}{ Positive controls } \\
\hline \multicolumn{3}{|c|}{ Antioxidant activity $\left(\mathrm{IC}_{50}\right.$ values, $\mu \mathrm{g} / \mathrm{mL}$ ) } & \multicolumn{3}{|l|}{ Trolox } \\
\hline TBARS formation inhibition & $23 \pm 2$ & $168 \pm 3$ & \multicolumn{3}{|l|}{$5.4 \pm 0.3$} \\
\hline OxHLIA, $\Delta t=60 \mathrm{~min}$ & $46.0 \pm 0.8$ & $70 \pm 1$ & \multicolumn{3}{|l|}{$19 \pm 1$} \\
\hline OxHLIA, $\Delta t=120 \mathrm{~min}$ & $67 \pm 1$ & $97 \pm 2$ & \multicolumn{3}{|l|}{$41 \pm 4$} \\
\hline \multicolumn{3}{|c|}{ Antimicrobial activity (MIC values, $\mathrm{mg} / \mathrm{mL}$ ) } & Ampicillin $(20 \mathrm{mg} / \mathrm{mL})$ & Imipenem $(1 \mathrm{mg} / \mathrm{mL})$ & Vancomycin $(1 \mathrm{mg} / \mathrm{mL})$ \\
\hline \multicolumn{6}{|l|}{ Gram-positive bacteria } \\
\hline Enterococcus faecalis & 10 & 10 & $<0.15$ & n.t. & $<0.0078$ \\
\hline Listeria monocytogenes & 20 & 20 & $<0.15$ & $<0.0078$ & n.t. \\
\hline MRSA & 5 & 5 & $<0.15$ & n.t. & 0.25 \\
\hline \multicolumn{6}{|l|}{ Gram-negative bacteria } \\
\hline Escherichia coli & 10 & 10 & $<0.15$ & $<0.0078$ & n.t. \\
\hline Klebsiella pneumoniae & $>20$ & $>20$ & 10 & $<0.0078$ & n.t. \\
\hline Morganella morganii & 20 & $>20$ & 20 & $<0.0078$ & n.t. \\
\hline Pseudomonas aeruginosa & 20 & 20 & $>20$ & 0.5 & n.t. \\
\hline Proteus mirabilis & 10 & 10 & $<0.15$ & $<0.0078$ & n.t. \\
\hline Neisseria gonorrhoeae & 20 & 20 & & & \\
\hline \multicolumn{6}{|l|}{ Yeast } \\
\hline Candida albicans & 20 & 20 & & & \\
\hline
\end{tabular}

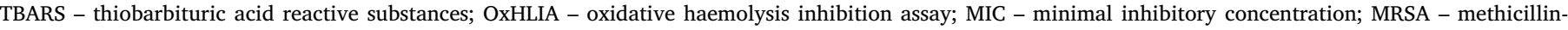
resistant Staphylococcus aureus. n.t. - not tested. $t$-Student test $p$-value $>0.001$

product, malondialdehyde (MDA), which reacts with thiobarbituric acid (TBA) forming MDA-TBA adducts that absorb at $532 \mathrm{~nm}$ (Estepa, Rodenas \& Martin; 2001). According to the data shown in Table 3, mulberry and grape seeds exhibited significant differences in the TBARS inhibition, at a $95 \%$ confidence level based on the $t$-Student test. Mulberry seeds showed an $\mathrm{IC}_{50}$ value of $23 \pm 2 \mu \mathrm{g} / \mathrm{mL}$, significantly lower than the one exhibited by grape seeds (168 $\pm 3 \mu \mathrm{g} / \mathrm{mL})$, meaning a greater efficiency against the oxidative agents produced in the in vitro peroxidation system. Peixoto et al. (2018) previously reported the TBARS antioxidant activity of Vitis vinifera seed bioresidue, with an $\mathrm{EC}_{50}$ close to $50 \mu \mathrm{g} / \mathrm{mL}$ for a hydromethanolic extract. Likewise, Raman et al. (2016) investigated the TBARS inhibition of the ethanolic extract from mulberry fruit and reported an $\mathrm{EC}_{50}>100 \mu \mathrm{g} / \mathrm{mL}$, which is significantly less effective than the one found in this study. In this sense, mulberry seed extracts can be exploitable for the preservation of food products and development of active films for packaging (Liu et al., 2019), since lipid peroxidation is one of the major reasons for the deterioration of food products during processing and storage.

On the other hand, the antihaemolytic properties of the extracts were assessed by the OxHLIA assay. This test evaluates the damage induced to the erythrocyte membrane, firstly by lipophilic radical generated by the thermal decomposition of AAPH and, subsequently, by lipophilic free radicals. These radical are neutralised by the antioxidants present in the tested extracts, which consequently keep the erythrocyte population intact for longer (Pinela et al., 2017). This bioassay uses peroxyl radicals (also found in vivo) as oxidants and sheep erythrocytes as oxidizable targets, therefore the results can be considered biologically relevant when compared to other methods (Pinela et al., 2017; Lockowandt et al., 2019). According to the data shown in Table 3, the extracts from mulberry seeds displayed a higher antihaemolytic activity than grape seeds. Significant differences were found out for the $\mathrm{IC}_{50}$ values at both times, at a $95 \%$ confidence level. The IC $\mathrm{I}_{50}$ values at $60 \mathrm{~min}$ were $46.0 \pm 0.8 \mu \mathrm{g} / \mathrm{mL}$ for mulberry seeds and $70 \pm 1 \mu \mathrm{g} / \mathrm{mL}$ for grape seeds, whilst at $120 \mathrm{~min}$ the OxHLIA IC ${ }_{50}$ values were $67 \pm 1 \mu \mathrm{g} / \mathrm{mL}$ and $92 \pm 2 \mu \mathrm{g} / \mathrm{mL}$ respectively. In this kinetic assay, the $\mathrm{IC}_{50}$ results were presented at two-time intervals, 60 and $120 \mathrm{~min}$, since natural extracts contain different amounts and profiles of antioxidant compounds, which show different behaviour towards free radicals in terms of capacity and rate scavenging (Lockowandt et al., 2019).

Therefore, mulberry seed extracts exhibited a statistically significant higher antioxidant activity in vitro in both, TBARS and OxHLIA assays. This greater radical scavenging ability of mulberry seeds could be attributable to the major content of ellagic acid and gallotannins, which have been reported to ameliorate the increased of lipid peroxides and hydroperoxides in rats (Shivashankara et al., 2015).

In both studies, trolox was used as a positive control and provided significantly the highest protection ( $p$-value $<0.05$ ) against lipid and erythrocytes membrane oxidation by radical spices (Table 3 ), since it is a pure standard.

\subsubsection{Cytotoxic and antimicrobial activities}

According to the obtained results (data not shown), no growth inhibition was observed for the tested cancer cell lines, by the extracts at the maximum tested concentration evaluated $(400 \mu \mathrm{g} / \mathrm{mL})$. Therefore, both mulberry and grape seed extracts presented no cytotoxic potential. Likewise, non-toxic effects against non-tumour primary culture PLP were verified, meaning that these extracts do not cause cell damage to healthy cell lines. This limited antiproliferative activity is in accordance with the previous observations of Peixoto et al. (2018), which reported $\mathrm{GI}_{50}$ concentrations higher than $200 \mu \mathrm{g} / \mathrm{mL}$ of grape seed hydromethanolic extracts for MCF-7 and HeLa tumour cells; and no growth inhibition for NCI-H460, HepG2 or normal liver cells with concentrations up to $400 \mu \mathrm{g} / \mathrm{mL}$. Additionally, the low cytotoxicity activity of Morus nigra L. extracts is in accordance with that observed by Turan et al. (2017), which reported $\mathrm{IC}_{50}$ values up to $370 \mu \mathrm{g} / \mathrm{mL}$ of fruit DMSO extracts when investigated human prostate adenocarcinoma (PC3) and normal fibroblast cells.

Regarding the antimicrobial activity, the action mode of mulberry and grape seed́s extracts against clinical human pathogens was investigated. Both, mulberry and grape seed extracts showed antimicrobial activity against all the tested microorganisms (Table 3); except for Klebsiella pneumoniae, in which no growth-inhibition was detected for any of the extract concentrations evaluated (MIC > $20 \mathrm{mg} / \mathrm{mL}$ ). As it can be seen in Table 3, MIC values are equal for both seed types against the analysed microorganisms, with the exception of for Morganella morganii, in which mulberry seeds were more effective with a MIC of $20 \mathrm{mg} / \mathrm{mL}$; whilst grape seeds showed no activity (MIC $>20 \mathrm{mg} / \mathrm{mL}$ ). The most sensitive bacterium was meticilin resistant Staphylococcus aureus (MRSA), attaining a MIC of $5 \mathrm{mg} / \mathrm{mL}$, followed by Enterococcus faecalis, Escherichia coli and Proteus mirabilis with a MIC of $10 \mathrm{mg} / \mathrm{mL}$ of MIC; and finally, Listeria monocytogenes, 
Pseudomonas aeruginosa, Neisseria gonorrhoeae and Candida albicans yeast with MIC values of $20 \mathrm{mg} / \mathrm{mL}$. Attending to the lowest values of MIC (ranging down $5 \mathrm{mg} / \mathrm{mL}$ for MRSA) and to the bacteria susceptibility, is possible to say that Gram-positive bacteria were found to be slightly more sensitive to the presence of mulberry and grape seed extracts. This fact can be attributable to the grater lipid barrier present in Gram-negative bacteria, which seems to limit the access of antimicrobial agents within the cells (Poveda et al., 2018). Other authors have also reported a lower inhibition to Gram-negative bacteria against oenological extracts. Delgado Adámez et al. (2012) observed that aqueous extracts from Vitis vinifera L. seed bioresidues exhibited antibacterial action against Listeria innocua and Staphylococcus aureus with MIC values of $100 \mu \mathrm{L} / \mathrm{mL}$. Additionally, Peixoto et al. (2018) described MIC values of 2.5 and $5 \mathrm{mg} / \mathrm{mL}$ in hydromethanolic extracts from grape seeds against Enterococcus faecalis, MRSA and methicillin susceptible Staphylococcus aureus.

In general, the inhibitory effects of mulberry and grape seeds extracts could be ascribed to their phenolic composition, confirmed to be the most important compounds active against bacteria (Delgado Adámez et al., 2012). Phenolic acids were the predominant compounds in both studied samples, although each of them presented different phenolic amounts and profiles, either in terms of phenolic profile or in terms of contents (Table 2). Grape seeds were found to present a total amount of phenolic acids much higher than mulberry seeds, whilst in the case of total other flavonoids this proportion was reversed (Table 2). Although the amount of total phenolic compounds was highly greater in the case of grape seeds ( $45 \mathrm{mg} / \mathrm{g}$ versus $8.02 \mathrm{mg} / \mathrm{g}$ in mulberry seeds), the major compounds were type-B polymeric proanthocyanidins, which summed up to $33.4 \mathrm{mg} / \mathrm{g}$, whilst the most abundant phenolic compounds in mulberry seeds were gallic acid derivatives (Table 2). Nevertheless, some researchers have demonstrated that the bioactivity of procyanidins varied based on their polymerization degree, so that as the polymerisation increases, the bioactivities are significantly reduced (Bai et al., 2019). This fact could explain why the behavior of both extracts against the analyzed microorganism was similar. Therefore, those extracts obtained from mulberry seeds resulted to be more effective against bacterial growth, likely due to the major presence of bioactive compounds with antibacterial properties; such as ellagic acid and gallotannins (Gomes et al., 2018) or quercetin; which have been reported to inhibit the DNA gyrase and therefore impaired bacterial reproduction (Cushnie \& Lamb, 2005).

\section{Conclusions}

The valorization of mulberry and grape seed wastes for the production of antioxidant-rich ingredients with health benefits is a sustainable strategy that can support the circular bio-economy and may help to address one of the main social challenges today, that is the waste amounts generated by the food industry.

The grape and mulberry extracts exhibited high contents in organic acids, mainly oxalic and quinic acids; whilst mulberry seeds were richer in tocopherols, predominantly $\gamma$-tocopherol. Phenolic compounds were predominant in grape seed wastes, mostly found as type B catechin trimers and dimers. These phenolic compounds were also found in mulberry seeds at lower concentrations; which suggests both wastes as readily exploitable sources of catechin and conjugates. Moreover, mulberry seeds contained significant amounts of ellagic acid derivatives; which are likely to play an important role in the lipid peroxides and hydroperoxides inhibition; as well as in the antimicrobial activity.

Regarding the bioactivities, the antioxidant activity assays showed that the extract from mulberry seeds was more efficient in inhibiting the formation of TBARS and the hemolysis of the erythrocyte's membrane. These results highlight the potential of mulberry extracts to be used as a preservative for instance, in extending the shelf life of food products or to act as healthcare agents in the pharmaceutical sector.

The antimicrobial activity, similar for both kind of extracts, highlighted the efficiency against methicillin-resistant Staphylococcus aureus (MRSA). On the other hand, no cytotoxicity was achieved against tumor and normal cells meaning that these extracts are not effective for cytotoxic purposes at the concentration of $400 \mu \mathrm{g} / \mathrm{mL}$.

Overall, the obtained results supported the recovery of valuable compounds as a cost-effective and sustainable strategy for wineries and mulberry juice production.

\section{CRediT authorship contribution statement}

Esther Gómez-Mejía: Methodology, Investigation, Writing - original draft. Custódio Lobo Roriz: Methodology, Writing - review \& editing. Sandrina A. Heleno: Methodology, Writing - review \& editing, Writing - original draft. Ricardo Calhelha: Methodology. Maria Inês Dias: Methodology. José Pinela: Methodology. Noelia RosalesConrado: Conceptualization, Methodology, Writing - review \& editing. María Eugenia León-González: Conceptualization, Methodology, Writing - review \& editing. Isabel C.F.R. Ferreira: Conceptualization, Methodology, Writing - review \& editing. Lillian Barros: Conceptualization, Methodology, Writing - review \& editing.

\section{Declaration of Competing Interest}

The authors declare that they have no known competing financial interests or personal relationships that could have appeared to influence the work reported in this paper.

\section{Acknowledgements}

The authors are grateful to the Foundation for Science and Technology (FCT, Portugal) for financial support by national funds FCT/MCTES to CIMO (UIDB/00690/2020); C. L. Roriz PhD's grant (SFRH/BD/117995/2016), L. Barros to FCT, P.I., through the institutional scientific employment program-contract for their contract and the individual scientific employment program-contract for S.A. Heleno's contract. To Eramus + grant (P BRAGAC01) and the Complutense University of Madrid, Spain for the preodoctoral grant [CT17/17-CT18/17] of E. Gómez-Mejía. In addition, to the Complutense University of Madrid, Spain for the preodoctoral grant [CT17/17-CT18/17] of E. Gómez-Mejía. In addition, to the companies Ponto Agricola Lda. (Portugal) and Terras Gaudas (Spain) for providing the sample by-products. The authors are grateful to FEDER-Interreg España-Portugal programme for financial support through the project 0377_Iberphenol_6_E.

\section{References}

Abdel-Hamid, N. S., Abdel-Khalek, H. H., Mattar, Z. A., Abou-Taleb, K. A., \& Ramadan, E. M. (2017). Screening of some Egyptian plant extracts for biological activity against some pathogenic bacteria. Arab Universities Journal of Agricultural Sciences, 25(2), $377-386$.

Alagawany, M., Abd El-Hack, M. E., Farag, M. R., Gopi, M., Karthik, K., Malik, Y. S., \& Dhama, K. (2017). Rosmarinic acid: Modes of action, medicinal values and health benefits. Animal Health Research Reviews, 18(2), 167-176.

Aldubayan, M. A. (2018). Qualitative and quantitative characterization of biologically active compounds of red grape (Vitis vinifera) seeds extract. Journal of Bioscience and Applied Research, 4(4), 410-417.

Bai, R., Cui, Y., Luo, L., Yuan, D., Wei, Z., Yu, W., \& Sun, B. (2019). A semisynthetic approach for the simultaneous reaction of grape seed polymeric procyanidins with catechin and epicatechin to obtain oligomeric procyanidins in large scale. Food Chemistry, 278, 609-616.

Barros, L., Pereira, E., Calhelha, R. C., Dueñas, M., Carvalho, A. M., Santos-Buelga, C., \& Ferreira, I. C. F. R. (2013). Bioactivity and chemical characterization in hydrophilic and lipophilic compounds of Chenopodium ambrosioides L. Journal of Functional Foods, 5(4), 1732-1740.

Bessada, S. M. F., Barreira, J. C. M., Barros, L., Ferreira, Isabel C. F. R., \& Oliveira, M. Beatriz P. P. (2016). Phenolic profile and antioxidant activity of Coleostephus myconis (L.) Rchb.f.: An underexploited and highly disseminated species. Industrial Crops and Products, 89, 45-51.

Cushnie, T. P. T., \& Lamb, A. J. (2005). Antimicrobial activity of flavonoids. International Journal of Antimicrobial Agents, 26(5), 343-356. 
Delgado Adámez, J., Gamero Samino, E., Valdés Sánchez, E., \& González-Gómez, D. (2012). In vitro estimation of the antibacterial activity and antioxidant capacity of aqueous extracts from grape-seeds (Vitis vinifera L.). Food Control, 24(1), 136-141.

Dopico-García, M. S., Valentão, P., Guerra, L., Andrade, P. B., \& Seabra, R. M. (2007). Experimental design for extraction and quantification of phenolic compounds and organic acids in white "Vinho Verde" grapes. Analytica Chimica Acta, 583(1), 15-22.

Du, C., Abdullah, J. J., Greetham, D., Fu, D., Yu, M., Ren, L., Li, S., \& Lu, D. (2018). Valorization of food waste into biofertiliser and its field application. Journal of Cleaner Production, 187, 273-284.

Estepa, V., Rodenas, S., \& Martin, M. C. (2001). A optimized method for the analysis of the lipidic peroxidation in human serum. Anales-Real Academia de Farmacia, 447-462.

Ghate, S., Kesharwani Ph D, Siddharth S, Madiyar, F., \& Pandey Ph D, Sonali R (2019). Product Development from Apple, Grapes and Berries Food Waste: Market Research, Industry Analysis and Opportunity Assessment.

Gomes, F., Martins, N., Barros, L., Rodrigues, M. E., Oliveira, M. Beatriz P. P., Henriques, M., \& Ferreira, Isabel, C. F. R. (2018). Plant phenolic extracts as an effective strategy to control Staphylococcus aureus, the dairy industry pathogen. Industrial Crops and Products, 112, 515-520.

Gültekin-Özgüven, M., Karadağ, A., Duman, S., Özkal, B., \& Özçelik, B. (2016). Fortification of dark chocolate with spray dried black mulberry (Morus nigra) waste extract encapsulated in chitosan-coated liposomes and bioaccessability studies. Food Chemistry, 201, 205-212.

Huang, H., Chang, Y., Wu, C., Hung, C., \& Wang, C. (2011). Anthocyanin-rich Mulberry extract inhibit the gastric cancer cell growth in vitro and xenograft mice by inducing signals of p38/p53 and c-jun. Food Chemistry, 129(4), 1703-1709.

Jordão, A. M., \& Cosme, F. (Eds.). (2018). Grapes and Wines: Advances in Production, Processing, Analysis and Valorization. BoD-Books on Demand.

Kim, E., Yu, M., Lee, Y., Leem, H., Kim, S., Kang, D., \& Choi, S. (2010). Comparison of functional constituents and biological activity of the seed extracts from two mulberry fruits. Preventive Nutrition and Food Science, 15(2), 98-104.

Koyuncu, F. (2004). Organic acid composition of native black mulberry fruit. Chemistry of Natural Compounds, 40(4), 367-369.

Li, F., Zhang, B., Chen, G., \& Fu, X. (2017). The novel contributors of anti-diabetic potential in mulberry polyphenols revealed by UHPLC-HR-ESI-TOF-MS/MS. Food Research International, 100, 873-884.

Liu, Y., Qin, Y., Bai, R., Zhang, X., Yuan, L., \& Liu, J. (2019). Preparation of pH-sensitive and antioxidant packaging films based on $\mathrm{\kappa}$-carrageenan and mulberry polyphenolic extract. International Journal of Biological Macromolecules, 134, 993-1001.

Lockowandt, L., Pinela, J., Roriz, C. L., Pereira, C., Abreu, R. M. V., Calhelha, R. C., Alves, M. J., Barros, L., Bredol, M., \& Ferreira, Isabel, C. F. R. (2019). Chemical features and bioactivities of cornflower (Centaurea cyanus L.) capitula: The blue flowers and the unexplored non-edible part. Industrial Crops and Products, 128, 496-503.

Mena, P., Sánchez-Salcedo, E. M., Tassotti, M., Martínez, J. J., Hernández, F., \& Del Rio, D. (2016). Phytochemical evaluation of eight white (Morus alba L.) and black (Morus nigra L.) mulberry clones grown in Spain based on UHPLC-ESI-MS ${ }^{\mathrm{n}}$ metabolomic profiles. Food Research International, 89, 1116-1122.

Mohan, A., \& Pohlman, F. W. (2016). Role of organic acids and peroxyacetic acid as antimicrobial intervention for controlling Escherichia coli O157:H7 on beef trimmings. LWT - Food Science and Technology, 65, 868-873.

Mosayebi, V., \& Tabatabaei Yazdi, F. (2018). Optimization of microwave assisted extraction (MAE) of pectin from black mulberry (Morus nigra L.) pomace. Journal of Food and Bioprocess Engineering, 2(1), 25-40.

Natić, M. M., Dabić, D.Č., Papetti, A., Akšić, M. M. F., Ognjanov, V., Ljubojević, M., \& Tešić, Ž. L. (2015). Analysis and characterisation of phytochemicals in mulberry (Morus alba L.) fruits grown in Vojvodina, North Serbia. Food Chemistry, 171, 128-136.
Okatan, V. (2018). Phenolic compounds and phytochemicals in fruits of black mulberry (Morus nigra L.) genotypes from the Aegean region in Turkey. Folia Horticulturae, 30(1), 93-101.

Peixoto, C. M., Dias, M. I., Alves, M. J., Calhelha, R. C., Barros, L., Pinho, S. P., \& Ferreira, I. C. (2018). Grape pomace as a source of phenolic compounds and diverse bioactive properties. Food Chemistry, 253, 132-138.

Petropulos, V. I., Dörnyei, Á., Stefova, M., Stafilov, T., Vojnoski, B., Márk, L., ... Kilár, F. (2014). Application of a novel small-scale sample clean-up procedure prior to MALDI TOF-MS for rapid pigment fingerprinting of red wines. Food Analytical Methods, 7(4), 820-827.

Pinela, J., Barros, L., Carvalho, A. M., \& Ferreira, Isabel C. F. R. (2012). Nutritional composition and antioxidant activity of four tomato (Lycopersicon esculentum L.) farmer' varieties in Northeastern Portugal homegardens. Food and Chemical Toxicology, 50(3), 829-834.

Pinela, J., Prieto, M. A., Barreiro, M. F., Carvalho, A. M., Oliveira, M. Beatriz P. P., Curran, T. P., \& Ferreira, Isabel C. F. R. (2017). Valorisation of tomato wastes for development of nutrient-rich antioxidant ingredients: A sustainable approach towards the needs of the today's society. Innovative Food Science \& Emerging Technologies, 41, $160-171$.

Pires, Tânia C. S. P., Dias, M. I., Barros, L., Calhelha, R. C., Alves, M. J., Oliveira, M. Beatriz P. P., Santos-Buelga, C., \& Ferreira, Isabel C. F. R. (2018). Edible flowers as sources of phenolic compounds with bioactive potential. Food Research International, 105, 580-588.

Poveda, J. M., Loarce, L., Alarcón, M., Díaz-Maroto, M. C., \& Alañón, M. E. (2018), Revalorization of winery by-products as source of natural preservatives obtained by means of green extraction techniques. Industrial Crops and Products, 112, 617-625.

Raman, S. T., Ganeshan, A. K., Gounder, P., Chen, C., Jin, C., Li, S., Chen, H., \& Gui, Z (2016). In vitro and in vivo antioxidant activity of flavonoid extracted from mulberry fruit (Morus alba L.). Pharmacognosy Magazine, 12(46), 128.

Ramón-Gonçalves, M., Gómez-Mejía, E., Rosales-Conrado, N., León-González, M. E \& Madrid, Y. (2019). Extraction, identification and quantification of polyphenols from spent coffee grounds by chromatographic methods and chemometric analyses. Waste Management, 96, 15-24.

Sabir, A., Unver, A., \& Kara, Z. (2012). The fatty acid and tocopherol constituents of the seed oil extracted from 21 grape varieties (Vitis spp.). Journal of the Science of Food and Agriculture, 92(9), 1982-1987.

Sabliov, C. M., Fronczek, C., Astete, C. E., Khachaturyan, M., Khachatryan, L., \& Leonardi, C. (2009). Effects of temperature and UV light on degradation of $\alpha$-tocopherol in free and dissolved form. Journal of American Oil Chemists' Society, 86(9), 895-902.

Shivashankara, A. R., Venkatesh, S., Bhat, H. P., Palatty, P. L., \& Baliga, M. S. (2015). Chapter 17 - Can phytochemicals be effective in preventing ethanol-induced hepatotoxicity in the geriatric population? An evidence-based revisit. Foods and Dietary Supplements in the Prevention and Treatment of Disease in Older Adults, 163-170.

Tomas, M., Toydemir, G., Boyacioglu, D., Hall, R., Beekwilder, J., \& Capanoglu, E. (2015). The effects of juice processing on black mulberry antioxidants. Food Chemistry, 186, 277-284.

Turan, I., Demir, S., Kilinc, K., Burnaz, N. A., Yaman, S. O., Akbulut, K., Mentese, A., Aliyazicioglu, Y., \& Deger, O. (2017). Antiproliferative and apoptotic effect of Morus nigra extract on human prostate cancer cells. Saudi Pharmaceutical Journal, 25(2), 241-248.

Vaz, J. A., Heleno, S. A., Martins, A., Almeida, G. M., Vasconcelos, M. H., \& Ferreira, Isabel C. F. R. (2010). Wild mushrooms Clitocybe alexandri and Lepista inversa: In vitro antioxidant activity and growth inhibition of human tumour cell lines. Food and Chemical Toxicology, 48(10), 2881-2884.

Zhang, H., Ma, Z. F., Luo, X., \& Li, X. (2018). Effects of mulberry fruit (Morus alba L.) consumption on health outcomes: A mini-review. Antioxidants (Basel, Switzerland), 7(5), 69. 